\title{
Epistemología de la teoría literaria: objeto y método en el formalismo ruso
}

\section{Epistemology of Literary Theory: Object and Method in Russian Formalism}

\author{
Roberto Chuit Roganovich \\ Universidad Nacional de Córdoba, Argentina \\ r.chuitroganovich@gmail.com
}

\section{Resumen}

En el presente trabajo se analizará desde una perspectiva althusseriana el objeto de estudio y la metodología del formalismo ruso. En primera instancia se intentará abordar el problema de la "abstracción científica", como así también los sucesivos acercamientos por parte de la escuela formal a la definición, relativamente estable a lo largo de sus años de actividad, del objeto y el método de estudio. En segunda instancia se intentarán abordar dos principios fundamentales del formalismo ruso (el de la existencia efectiva de los textos literarios y el de la presuposición de una literaturiedad), atendiendo no solo a sus implicancias epistemológicas, sino también al impacto que estos dos principios tuvieron en la teoría literaria de principios de siglo xx.

Palabras clave: Objeto, método, formalismo ruso, teoría literaria, epistemología, Althusser.

\begin{abstract}
In the present work the object of study and the methodology of Russian formalism will be analyzed from an Althusserian perspective. In the first instance, we will try to address the problem of "scientific abstraction", as well as the successive approaches by the formal school to the definition, relatively stable throughout its years of activity, of the object and the method of study. In second instance we will try to address two fundamental principles of Russian formalism (the effective existence of literary texts, and the presupposition of a literariness), not only taking into account their epistemological implications, but also the impact that these two principles had in the literary theory of the early twentieth century.
\end{abstract}

Keywords: Object, method, Russian formalism, literary theory, epistemology, Althusser. 


\section{Introducción}

Si el formalismo aceptó, por caso, la idea según la cual la literatura es una experiencia específica que guarda diferencias concretas no solo con otras experiencias del arte sino también con el conjunto todo de las prácticas sociales, entonces es también esperable, o al menos coherente, reservar un aparato teórico también específico construido hacia y para la literatura; si existe la posibilidad de hecho de preguntarse por una historia de la literatura (de ella y solo ella), en tanto - y aquí aceptaríamos el principio formalista - la literatura es una experiencia radicalmente otra, entonces también es posible preguntarse, en cuanto correlato de la historia primera, por una historia de la teoría que la ha abordado. Liberar a la literatura a su aparente autonomía (entendiendo este concepto en clave teórica) sin hacer lo propio con el aparato que intenta dar una palabra acerca de ella es sin duda problemático: si la literatura es considerada por el formalismo como una experiencia marcada en su positividad es porque el pensamiento mismo la ha determinado, a fines analíticos y programáticos, de ese modo; si las notas características de la literatura son específicas es porque el pensamiento que la piensa es también él específico, y específicamente dirigido. En otras palabras, la existencia misma de la literatura en tanto tal, esto es, como conjunto de relaciones, como conjunto determinado de fenómenos concretos que responden de forma vinculada y vinculante a una signatura categorial, no es sino el producto definitivo de la práctica teórica. Así, la autonomía de la literatura, su carácter diferencial (pero también aquello que el formalismo llamó la "literaturiedad"), es menos un rasgo distintivo, puro y fácilmente reconocible de aquello que entendemos por literatura, sino por el contrario la sutura abstracta (a través la práctica teórica) que hace posible su pensamiento. ${ }^{1}$

1 Se nos perdone este extenso paréntesis. La relación objeto de nuestro trabajo (la relación entre la teoría, su objeto y su método) no es en modo alguno transparente o meramente intuitiva, ya que las simultáneas determinaciones que funcionan como condición de emergencia de un discurso como el del formalismo ruso podría, y más bien debería, ser abordado desde múltiples dispositivos teóricos. Aun así, pretendemos reservar nuestro análisis a un estricto campo epistemológico. Nos diferenciamos, por ejemplo, de la contribución de Victor Erlich, que consideramos no puede dejar de ser reconocida en toda su relevancia. Las primeras líneas del prólogo a la obra El formalismo ruso (1974) son más que elocuentes. Erlich dice, de forma lacónica: "Este estudio tiene por objeto subrayar el desarrollo histórico y exponer la doctrina crítica del formalismo ruso" (17); y más adelante, justificando brevemente su propuesta, dice: "A decir verdad, si hubiera que monolitizar la organización de este estudio, habría sido preciso sacrificar o sus aspectos históricos o sus aspectos analíticos. También hubiera sido posible establecer brevemente el marco histórico de referencia y concentrarse luego en la exposición sistemática de los principios formalistas. Pero tal método no habría hecho justicia a las diferencias antagónicas entre las fases sucesivas de la escuela formalista o a su interacción con el escenario cultural ruso de los años 1915-30. También habría podido adoptarse el procedimiento opuesto: presentar la teoría formalista en el cuadro de su evolución. Pero una exposición dinámica de la doctrina formalista, como esa habría sido, que examinara sucesivamente las implicaciones teóricas de cada fase individual, implicaba inconvenientes mayores. No hubiera conseguido compendiar, con tantas palabras, la contribución formalista total en los varios campos de la teoría literaria, prosodia, estilística, teoría de la prosa, teoría de la historia literaria" (18). No es casual que su libro se divida convenientemente en dos grandes bloques: el primero, llamado Historia, donde se intenta abordar brevemente "el marco histórico de referencias" (filosóficas, estéticas, artísticas y políticas) circundantes al formalismo ruso; y el segundo, llamado Doctrina, que se centra en la "exposición sistemática de los principios formalistas", intentando no dejar de lado los múltiples campos de la teoría literaria abordada por la escuela formal. La puerta de ingreso de la escuela 
No hay en esta perspectiva, deudora de la tradición marxista, desviación idealista alguna. No derivamos la existencia de lo real a partir de una consigna teórica. Vivimos, sin más, en lo concreto. Lo concreto nos rodea, nos circunda. Sin embargo, la experiencia que mantenemos con lo concreto no es en ningún modo transparente, automática e idílica (como pretendía el Bacon de La nueva Atlántida); más bien es la relación que mantenemos con lo concreto la que está mediada por la abstracción. En términos generales, Althusser, en Iniciación a la filosofía para los no filósofos, dice:

La abstracción no es la separación de una parte perteneciente al todo concreto. La abstracción está ligada a lo concreto, proviene de lo concreto de una manera que puede variar (el lenguaje no fue abstraído de lo concreto como el derecho ni como los gestos abstraídos de toda práctica). Pero lo propio de la abstracción es ser algo más que una parte de lo concreto, puesto que agrega algo a lo concreto. ¿Qué le agrega? La generalidad de una relación (lingüística, jurídica, social, ideológica) que concierne a lo concreto. Mejor aún: esta relación domina inadvertidamente lo concreto y es la que constituye lo concreto como concreto (76).

Habría según Althusser entonces un ciclo: al comienzo, lo concreto, luego lo abstracto y luego lo concreto nuevamente, reapropiado por la abstracción. En este marco, existiría un concreto no apropiado por la abstracción y que, por esta razón, no es nada; pero también un concreto - un concreto apropiado- producido como concreto a partir de la abstracción.

\section{Abstracción y apropiación}

Tenemos, entonces, dos problemas centrales a resolver: el primero, el del proceso de la abstracción y el de la apropiación de lo concreto por la abstracción (y con ello, el

formal al pensamiento de Occidente no podía ser realizado de otra manera: era menester para Erlich exponer en forma conjunta no solo la doctrina formalista en su especificidad evolutiva, sino también, y sobre todo, el campo de discusiones filosóficas activas en los primeros años del siglo xx ruso. Esta exigencia, creemos, estuvo más ligada al estado de las discusiones acerca del formalismo ruso (y de la estética en general) en los campos de saber filosóficos europeos cuanto a un deber teórico nítido: se preparaba la evolución estructuralista de los 60 en Francia, y para poder dar cuenta de la cualidad distintiva de esta renovación analítica era preciso exponer la lógica de lo que algunos consideraban su comienzo, de su desarrollo y su migración. Es por eso que en Erlich aparece como un indispensable expositivo un elemento que para nosotros no es sino el derivado obligado de un diagnóstico certero. Es claro a esta altura por qué consideramos que ya no es indispensable (aunque sí podría resultar interesante) realizar un trabajo como el de Erlich. Nuestros apremios (políticos, filosóficos, epistemológicos y estéticos) son otros. Por estas razones es que nuestro trabajo va a adolecer de ciertas ausencias. En específico, por una parte, el estudio de las condiciones filosóficas, científicas y estéticas que hicieron posible - de forma positiva o negativa - la emergencia de un discurso como el del formalismo ruso (como por ejemplo el neopositivismo y el marxismo - donde se enmarca la contribución del círculo bajtiniano-); por otra parte, el estudio de los discursos circulantes en la Europa y Rusia de principio de siglo xx con los cuales el formalismo ruso mantuvo relaciones (ya sea beligerantes o de apoyo mutuo), como ser la corriente futurista de las vanguardias, el simbolismo y la crítica impresionista de las academias rusas. 
mentado par práctica-teoría); el segundo, el problema de la especificidad de la abstracción que atañe a la práctica científica. ${ }^{2}$

Con relación al primer problema podemos decir que no consideramos - como lo hizo de forma recurrente la tradición idealista del pensamiento, al presuponer siempre la existencia efectiva de las formas puras del conocimiento- que existe una obligada jerarquización entre opuestos que termina por subsumir la práctica a la teoría. Creemos, más bien, que el par práctica-teoría designa menos dos objetos diferenciados cuanto una relación específica y concomitante entre términos, en última instancia, inseparables. Así, es a partir de la abstracción que podemos nombrar, conocer, designar, comprender, en suma, apropiarnos de lo concreto; pero a la vez es a partir de las condiciones prácticas (esto es, sociales) de determinadas representaciones del mundo que la abstracción se lleva a cabo. A diferencia entonces de cualquier postura que pueda tomar como certera la apropiación directa y automática - esto es, no mediada - de lo concreto, consideramos, como marxistas, que existe siempre una determinación de la teoría por la práctica, en tanto es la práctica la que establece las directivas ulteriores del proceso de abstracción.

El segundo problema es también de vital importancia. Reducir toda forma de abstracción al mismo diagrama de operaciones es irresponsable. Es necesario aclararlo: no toda abstracción se hace efectiva a partir del mismo mapa de rutinas, ni mantiene la misma relación con lo concreto. La abstracción que el formalismo ruso puso en práctica para llevar a cabo su estudio de la literatura no puede dejar entonces de ser considerada también una muy específica forma de abstracción.

No podemos decir que la abstracción que caracterizó al formalismo fuese la que Althusser entiende por "abstracción técnica", y que operase sobre "objetos concretos, empíricos y sobre las operaciones que permiten obtener resultados concretos" (Althusser 82); no podemos decir que esta forma de abstracción refiriese al problema de la técnica y del saber hacer en las prácticas productivas, ya sea inmediata, o mediada a través de herramientas; no podemos decir que sea una forma de abstracción que establezca con lo concreto que pretende apropiar una relación de generalidad, en tanto la generalidad siempre supone una marcada limitación a la posibilidad inductiva y a la posibilidad de la conformación del concepto (que opera, por el contrario, en los campos de la universalidad). Tampoco podemos decir que la abstracción expuesta

2 Con el fin de desarrollar esta investigación - que comprende nuestra tesina de grado como también nuestro proyecto de tesis doctoral- se realizó un relevamiento de los aportes teóricos de la llamada epistemología francesa, tanto en su deriva "clásica" durante la década de los 50-60, como en su deriva contemporánea a partir de los años 2000. Este relevamiento fue esencial para comprender la actualidad del debate. En definitiva, para comprender cómo la pregunta por la posibilidad de una epistemología de la teoría literaria, problemática relativamente ausente durante las décadas de los 80 y 90, ha percibido en los últimos años una gran revitalización (de mano de nombres como Althusser, Macherey, Bessiere, Jablonka, Javeau, Louis, Schaeffer, entre otros). Los antecedentes relevados hicieron posible reconstruir no solo los principios teóricos sino también el conjunto de directrices metodológicas a partir de las cuales plantear el problema de la investigación. Así, las contribuciones de la llamada epistemología francesa permitieron entender que si existe para la teoría literaria un objeto específico y un método de análisis específico, definidos como producto de la práctica analítica de la teoría y no como su punto de partida, es porque la teoría literaria, al menos en un nivel analítico, es también una disciplina relativamente autónoma de análisis del discurso. 
por el formalismo ruso sea la que la escuela althusseriana entiende por "abstracción filosófica", donde aquello que figura como el fiel inalienable de la operación, como sí sucede en la filosofía idealista, sea la idea de totalidad. Todo indica, pues, que el formalismo, al abandonar toda filiación a la reflexión tradicional acerca del arte (en el sentido fuerte del término, esto es, la Estética), y al abandonar todo posible desembarco en una antropología especulativa, estaba también abandonando toda pretensión de totalidad —el problema del Sujeto que observaremos más adelante-. Tal vez la "modestia" formalista que supimos destacar no haya sido tal cosa, sino por el contrario la carta de presentación misma de su propuesta: el formalismo ruso no pretendió así extraer de la experiencia del arte la regla común de todo aquello que es (es decir, de todos los seres) sino solo las reglas universales de la literatura.

\section{La abstracción y la apropiación del formalismo ruso}

Habiendo hecho estas distinciones, creemos que la forma de abstracción que el formalismo puso en práctica para abordar el problema de la literatura fue la abstracción científica. Althusser la caracteriza del siguiente modo:

El conocimiento científico, en cambio, trata de los objetos directamente abstractos y dotados por ello de una abstracción que no es ya la generalidad, sino la universalidad. Un concepto científico, un teorema científico, una ley científica son válidos para todos los objetos definidos por ese concepto, ese teorema, esa ley, sin excepción, aunque la demostración científica se haya efectuado sobre un único caso, justamente, sobre un objeto abstracto que tiene la propiedad de representar al conjunto infinito de objetos de su tipo.

El salto de la generalidad a la universalidad, el resultado demostrado sobre un solo objeto abstracto que vale para todos los objetos de su tipo, es lo que cambia enteramente el alcance del conocimiento: este ya no está limitado a los casos observados, puesto que se extiende a todos los casos posibles de un mismo género. Las propiedades establecidas al estudiar un triángulo puro son válidas para todos los triángulos posibles o reales (83).

Abordamos la teoría formalista como una forma de abstracción científica en primera instancia porque vemos que existen ciertas concordancias esenciales entre lo que la escuela althusseriana entiende por este tipo de abstracción y la práctica teórica efectiva del formalismo ruso; en segunda instancia la abordamos como tal en tanto el formalismo ruso siempre abogó, por lo menos en sus declaraciones de principios, por el desarrollo de una teoría científica de lo literario.

Es probable que la gran mayoría de los representantes del formalismo ruso estudiados tuviesen un conocimiento al menos rudimentario de esto que estamos exponiendo. En su Curso de lingüística general, texto al que los formalistas habían 
accedido de forma iterativa, Ferdinand de Saussure ya explicaba los pormenores de los procesos de abstracción en la práctica científica:

Otras ciencias operan con objetos dados de antemano y que se pueden considerar en seguida desde diferentes puntos de vista. No es así en la lingüística. Alguien pronuncia la palabra española desnudo: un observador superficial se sentirá tentado de ver en ella un objeto lingüístico concreto; pero un examen más atento hará ver en ella sucesivamente tres o cuatro cosas perfectamente diferentes, según la manera de considerarla: como sonido, como expresión de una idea, como correspondencia del latín (dis)nudum, etc. Lejos de preceder el objeto al punto de vista, se diría que es el punto de vista el que crea el objeto, y, además, nada nos dice de antemano que una de esas maneras de considerar el hecho en cuestión sea anterior o superior a las otras (55).

Aquí de Saussure da los fundamentos necesarios para entender que 1) todo acercamiento a lo concreto es, en principio, una abstracción determinada en última instancia por las condiciones prácticas (esto es, sociales) que hacen posible esa abstracción; y que 2) toda abstracción científica construye, a la vez que su objeto, su propio régimen de invisibilidades, su propio campo de puntos ciegos.

El trabajo teórico es siempre entonces un trabajo de delimitación y definición retrospectiva que no debe 1) tomar por evidentes las caracterizaciones heredadas de los fenómenos que pretende abordar (trabaja, por el contrario, sobre y a partir de ellas), y que tampoco debe 2) reducir su propia práctica a un trabajo aplicacionista que replique los métodos utilizados en otros espacios del conocimiento. La teoría supone entonces dos principios, simultáneos y complementarios: el primero, que toda afirmación supone siempre algo, y que ese algo (las Generalidades con las que trabaja la ciencia, al decir althusseriano) debe ser despejado en orden a caracterizar los enunciados heredados; el segundo, que la particularidad del método es derivada de la determinación de la especificidad del objeto por la práctica teórica.

Planteado esto, podemos decir que en relación con el primer principio, aunque el formalismo ruso no haya tomado seriamente la puesta a punto con ciertas concepciones heredadas de aquello que se considera acerca de la literatura y de cómo debería ser abordada y, más aún, que haya justificado esta falta a través de una apuesta por el conocimiento sin presuposiciones (que Eichenbaum, por ejemplo, nunca dejó de defender con ahínco), no nos obliga a nosotros a replicarlo. En todo caso nos interesa llevar a cabo una reflexión sobre las influencias discursivas (filosóficas y científicas) determinantes en la formación del pensamiento formalista, y sobre las implicancias de la aceptación (a veces de forma inconsciente) de estas influencias. Con relación al segundo principio, consideramos que la institución de la teoría literaria (esto es, el fundamento de la posición que ocupa en el enorme universo de las prácticas teóricas) no debería, en tanto cada ciencia construye su propio objeto, reducirse al préstamo indiscriminado de categorías y propuestas metodológicas provenientes de otros campos del saber. 


\section{Dos presupuestos}

Presentar, por lo menos de manera fugaz, el tipo de abstracción que la escuela formal puso en operación para llevar a cabo su práctica analítica (es decir, la abstracción científica) nos sirvió para entender no solo las características generales de los enunciados heredados con los cuales el formalismo debió tratar, sino también para entender cuál era, en términos generales, el objetivo de su propia práctica teórica; en otras palabras: observar la concordancia entre la práctica teórica formalista y lo que Althusser entiende por abstracción científica nos permitió entender que, en orden a que el formalismo concretara su objetivo (la conformación de un objeto de estudio y su correspondiente método) iba a tener que operar retroactivamente sobre enunciados heredados acerca del arte y la literatura. Es la observación de este proceso - la conformación del objeto y el trabajo metodológico sobre él, siempre mediado por la reflexión de los enunciados heredados- sobre lo que va a versar el presente trabajo.

Dentro de este marco, creemos que existen dos presupuestos esenciales en el formalismo que nos gustaría examinar. El estudio de los fundamentos de estos dos presupuestos, en tanto guardan una pretensión de universalidad destacable (propia, como ya vimos, de la abstracción científica), puede arrojarnos conocimiento acerca del modo en el que los formalistas no solo entendieron su propia práctica sino también el modo en el que entendieron la literatura en cuanto tal.

Estos dos presupuestos son: 1) el de la existencia efectiva de textos literarios, y 2) el de la existencia de un rasgo distintivo y diferencial de la literatura (la literaturiedad).

\section{Hay textos: la existencia eterna del campo literario}

El primer supuesto que nos interesa revisar es aquel que en los más conocidos textos formalistas figura como una constatación de facto, como un reconocimiento básico y automático (y por eso, según este aparato, inalienable): el de la existencia efectiva de un fenómeno, por caso, el de los textos literarios. Así, el primer formalismo terminó por considerar que la existencia concreta de los textos literarios era irreductible a cualquier otro fenómeno que pudiese determinarlo siquiera de forma diferida, y que solo a partir de esa constatación era que se hacía posible una teoría de la literatura. En otras palabras: el reconocimiento (esta palabra es esencial) de la existencia de los textos de la literatura le permitió al formalismo sostener que el campo de observación que contenía los textos literarios había existido, mutatis mutandis, siempre, independientemente del conocimiento (es decir, independientemente del científico y su práctica), e independientemente de cualquier determinación extrínseca, y que su "descubrimiento" (es decir, el descubrimiento de este dominio) era la condición de posibilidad de una teoría que lo abordase. 
Es evidente: la afirmación de la existencia de un dominio, del campo de estudio de una ciencia en particular no constituye, rigurosamente, ni la definición minuciosa del par complementario objeto-método, ni tampoco la realización práctica de la teoría científica. Esta constatación aparente de facto pavimentó de hecho el camino para el desarrollo teórico de la escuela formal: todo sucedía en los comienzos del formalismo como si el cercamiento, o, como dijimos antes, la afirmación de la existencia de un dominio - el dominio literario- fuese suficiente para poner en marcha todo un enorme aparato analítico. Si en efecto esta constatación fue o no suficiente para el comienzo de la práctica analítica no es algo que nos preocupe en este momento. Nos preocupa, fundamentalmente, y con relación al problema de la abstracción que acabamos de exponer, la razón teórica de esta constatación.

La revisión de la razón teórica de esta constatación nos lleva a preguntarnos de forma directa por las condiciones mismas de una constatación de este calibre. Esta condición es, sin dudas, la representación de una relación abstracta, un diálogo, que el formalismo intentó establecer con aquello que creía que era su dominio de pensamiento; una relación que, sin embargo, nunca deja de contemplar el carácter de los elementos que participan en la ecuación. Y aquí aparece lo interesante: porque todo parece indicar que en la relación que planteó el formalismo no encontramos sino un sujeto dado, previo a todo conocimiento, libre de toda conminación, y también un objeto dado, previo a toda apropiación que pudiera haberse hecho de él a partir de diversos tipos de abstracción.

El problema del sujeto supuesto en esta relación de conocimiento, del sujeto dado, ya lo hemos tratado en otro trabajo nuestro acerca del formalismo, que se titula, "Notas breves para el estudio del formalismo ruso", y que aún no ha sido publicado. Este supuesto es, para decirlo de forma rápida, el que se esconde bajo la apuesta por un conocimiento sin presuposiciones (al decir de Eichenbaum). La apuesta por un conocimiento sin presuposiciones implica un conocimiento extraído (volveremos sobre esta palabra) de lo concreto por parte de un sujeto que no precisa de nada más que de sus facultades cognitivas para acceder a la verdad de los objetos que lo circundan, de un sujeto cuya observación misma no se encuentra bajo ningún término mediada por las generalidades que han establecido como válidas las relaciones prácticas que se han establecido con este concreto en particular.

El problema del objeto, por el contrario, no nos obliga a realizar un recorrido tan exhaustivo. En múltiples textos formalistas se afirma, de algún modo u otro, la existencia previa, a toda instancia de abstracción teórica, del dominio de las obras de la literatura, de la materialidad de los textos que, de forma espontánea, formarían parte de este extraño y complejo campo que es la literatura. El mismo Eichenbaum afirma, en el texto en el que pretende presentar las líneas generales de la escuela en la que participó durante largo tiempo, que "En los hechos, nosotros no hablamos ni discutimos de ninguna metodología. Hablamos y podemos hablar únicamente de algunos principios teóricos sugeridos por el estudio de una materia concreta y de sus 
particularidades específicas y no por tal o cual sistema acabado, sea metodológico o estético" (Eichenbaum 11).

Althusser explica con suma delicadeza esta desviación recurrente en la tradición empirista, que refiere no tanto al estatuto del objeto y del sujeto que intervienen en el proceso de conocimiento, sino más bien a la problemática de base de esta relación:

La concepción empirista del conocimiento pone en escena un proceso que acaece entre un objeto dado y un sujeto dado. Poco importa, a este nivel, el status de este sujeto (si es psicológico, histórico o no) y de este objeto (si es discontinuo o continuo, móvil o fijo). Este status no concierne sino a la definición precisa de las variaciones de la problemática de base, que es la única que aquí nos interesa. Sujeto y objeto dados, y por tanto anteriores al proceso del conocimiento, definen de por sí un cierto campo teórico fundamental, pero que, en este estado, todavía no puede enunciarse como empirista. Lo que lo define como tal es la naturaleza del proceso del conocimiento; dicho de otro modo, cierta relación, que define al conocimiento como tal, en función del objeto real del que se dice conocimiento (Althusser 41).

En este marco, es necesario - para poder reconstruir la dirección con respecto a la cual todo el aparato teórico de la escuela formal intentó dirigirse- desandar la pregunta que el formalismo intentó hacerle a ese dominio (el literario) que parecía haber existido siempre. Es justamente aquí, en esta apertura, en esta cesura que resguarda el carácter autotélico de todo orden, donde podemos advertir de forma más transparente la influencia positivista en el programa de estudio formalista.

\section{"La totalidad expuesta" (el conocimiento en posesión del objeto)}

Dijimos que el formalismo presentaba como evidente la constatación de un dominio; que una constatación de este calibre suponía una relación, fuertemente jerarquizada, entre un objeto y un sujeto dados, entre un sujeto cuya consciencia se completa conceptualmente siempre de forma fidedigna a lo real a través de los datos de la experiencia y un objeto previo a la instancia de su conocimiento. En este marco, pudimos observar el problema del sujeto en el formalismo ruso a través de un rodeo por la presentación del programa de la escuela formal. Nos queda entonces seguir desarrollando la problemática del objeto.

Es, sin lugar a dudas, cierto que los objetos existen de forma previa a su conocimiento, que existen independientemente de la práctica científica que "extrae" sus rasgos distintivos (ya lo dijimos anteriormente, lo real no puede ser caracterizado por una categoría teórica, puesto que la relación sujeto-objeto idéntico de raigambre hegeliana podría llevarnos a poner en tela de juicio la existencia misma del mundo real). Si en definitiva existía una teoría era porque entendíamos que ella, volcándose 
sobre lo concreto, que la preexiste, podía apropiárselo presentándolo a posteriori como una apropiación de lo concreto por razón del pensamiento, y que este concreto apropiado luego retornaría a lo social como práctica para determinar nuevamente (en tanto Generalidad, al decir de Althusser) la apropiación que de él hace nuevamente la teoría (lo que la tradición marxista llama "determinación de la teoría por la práctica").

Tal concepción acerca del objeto (es decir, su preexistencia) no era suficiente para dotar de título de científico a la empresa formalista. El diagrama dominante en lo que respectaba a los mecanismos a través de los cuales el conocimiento científico era posible en los primeros años del siglo $\mathrm{xx}$, y el diagrama que los mismos formalistas intentaron replicar, requería otro tipo de justificaciones teóricas, mucho más complejas.

El neopositivismo lógico precisaba, en orden a establecer un objeto apto para el abordaje científico, un despeje de términos que erradicase del amplio campo de la ciencia todo fenómeno que no pudiese, en última instancia, verse sometido a una práctica experimental. En otras palabras: la condición para erradicar del pensamiento científico constructos teóricos que a los ojos de los positivistas resultaban dudosos (como el marxismo o el psicoanálisis), era que las cualidades del objeto al cual la teoría se acercase cayesen bajo el control de la verificación experimental. Esta negación de la posibilidad de un objeto de estudio imaginario suponía, en última instancia, que el objeto, además de preexistir a su conocimiento contuviese, ya en sí, la clave de su propio entendimiento. Althusser, en el capítulo "La abstracción científica y el idealismo" del ya mencionado libro Iniciación a la filosofía para los no filósofos dice:

Esta concepción supone la existencia de un objeto que sea no solo independiente de su conocimiento (esta tesis es materialista), sino que contenga en sí, de manera inmediata, su propio conocimiento, conocimiento que el científico solo tiene, por lo tanto, que extraer. Notemos al pasar que esta concepción, muy difundida en la conciencia ideológica de los científicos, sobre todo experimentales, no carece de una consistencia real, en la medida en que enuncia, aunque lo haga de manera desviada y, en consecuencia, falsa, una verdad: que el conocimiento producido por el trabajo del científico es sencillamente el conocimiento del objeto que existe independientemente de su conocimiento, fuera del trabajo del científico. Lo cual equivale a decir que el conocimiento de cualquier objeto le pertenece, aun antes de haber sido producido, incluso antes de ser conocido. Lo cual permite introducirlo de antemano, con toda justicia, en el objeto, puesto que ese conocimiento le pertenece de pleno derecho (Althusser 116).

Dentro de esta perspectiva, el formalismo ruso se vio conminado por la legitimidad de la práctica neopositivista a emular las características de los objetos considerados por el neokantismo como válidos, como así también de las herramientas técnicas utilizadas para su abordaje. A partir de este reconocimiento, decimos, el reconocimiento de la legitimidad de la práctica científica tal como el neopositivismo la 
entendía, la escuela formal intentó trasvasar las condiciones mismas de trabajo al estudio acerca de la literatura. Este desplazamiento es evidente en gran parte del formalismo. Tomemos por caso una figura un tanto díscola, que con muchas reservas y precaución debería ser considerado como un integrante de la escuela formal, como lo es Vladimir Propp. En las primeras páginas de su artículo "Las transformaciones de los cuentos fantásticos", destaca esta homologación, general y abusiva, no solo entre los objetos mismos de la lingüística y la biología, sino también en los procedimientos técnicos de su abordaje:

Se puede, por diversos conceptos, comparar el estudio de los cuentos con el de las formas orgánicas de la naturaleza. Tanto el folklorista como el naturalista se ocupan de fenómenos distintos que, sin embargo, son idénticos en su esencia. La cuestión del origen de las especies planteada por Darwin puede también plantearse en nuestro dominio. En el reino de la naturaleza, como en el que nos ocupa, no existe una explicación directa, completamente objetiva y absolutamente convincente de la semejanza de los fenómenos. Este hecho nos coloca ante un verdadero problema; $y$ en cada caso son posibles dos puntos de vista: o se afirma que para dos fenómenos que no tienen ni pueden tener ninguna relación exterior, su semejanza no nos conduce a una raíz genética común (teoría de la génesis independiente de las especies), o esta semejanza morfológica es interpretada como la consecuencia de un cierto vínculo genético (teoría del origen por metamorfosis o transformaciones que remontan a una cierta causa) (241).

\section{Imperio de la técnica (Identificación conocimiento-técnica)}

El empirismo sostiene que es posible una forma de conocimiento a partir del contacto directo con los objetos del mundo; que en última instancia, el acercamiento del observador (mediado nada más que por las facultades cognitivas del sujeto) es suficiente para que el objeto revele sus propiedades específicas y diferenciadas; y que, por tanto, las cualidades distintivas de los objetos no son, en tanto enunciados lógicos, el producto de la práctica científica sino más bien su condición (Bachelard 20). Esto supone siempre, dentro de este marco, que el objeto, que contiene siempre en su interior el conjunto de notas características que representan su especificidad, irrumpe en la teoría como aquello estable e incorruptible, desplazando la necesidad teórica de la construcción de un objeto de estudio. Se dirá entonces, y por derivación, que si en relación con este objeto hay un hecho que no refrenda lo que hasta tal o cual momento ha sido tomado por válido, no es porque nuestro objeto nos haya engañado, sino más bien porque no fue abordado de la manera "correcta" (es decir, el problema no es lo que creemos del objeto sino el método con el que lo abordamos). Este pensamiento recurrente en la tradición empirista, pero también presente de manera distinguida en el formalismo ruso, supone en última instancia que el conocimiento no es el producto 
de una práctica de abstracción específica, sino que el conocimiento bien podría ser reducido al perfeccionamiento de las herramientas de trabajo. ${ }^{3}$

Para ser un tanto más claros: este programa reduce la importancia teórica de la construcción del objeto de conocimiento a la vez que entroniza la tarea metodológica. La ciencia, como la entendía el formalismo, no necesitaba un objeto de estudio (teóricamente definido a partir de la abstracción mediada por las generalidades de la práctica), porque el objeto ya estaba allí, en el mundo; necesitaba más bien el perfeccionamiento de las herramientas de su abordaje. He aquí la entronización de la técnica por sobre la importancia teórica de la construcción del objeto de estudio. El mismo Todorov parece indicarlo al pasar, sin haber podido sin embargo exponer las consecuencias de estas desviaciones. En la "Presentación" a la más famosa antología del pensamiento formalista, Todorov dice:

Esta actitud ha reforzado el positivismo ingenuo de los formalistas: muy a menudo declaran a la cabeza de sus obras que la ciencia es independiente de toda teoría. De creerles, no existiría en su trabajo ninguna premisa filosófica o metodológica. Del mismo modo, ellos no tratan de sacar las consecuencias que surgen de sus trabajos, y aún menos de generalizarlas en una metodología de las ciencias humanas. No puede dejar de sorprender una declaración tal de parte de estos estudiosos que, negando todo valor autónomo a su método, han elaborado de hecho una de las doctrinas metodológicas más logradas: actualmente hasta se les podría reprochar el no haber pensado más que en la metodología. Esto muestra una vez más que, en ciencia, el positivismo ingenuo es siempre ilusorio; es más bien el índice de un fenómeno corriente en los empiristas: la falta de conciencia de sus propios medios, incluso de la esencia de sus actos (19).

Este meollo no es para nosotros menor. La escuela althusseriana defendería la propuesta de Marx según la cual, en oposición a las propuestas formalistas leídas más arriba, el objeto de conocimiento es, en su especificidad, "absolutamente distinto y diferente del objeto real” (Althusser 46): el objeto de conocimiento es, más bien, un producto exclusivo del conocimiento que lo produce, valga la redundancia, como un concreto de pensamiento. Lo real no puede ser caracterizado por una consigna teórica. Lo real es, estrictamente, lo real, aquello que existe independientemente del proceso de conocimiento. Del mismo modo como lo entiende Bachelard (178), creemos que el objeto real es un conjunto de operaciones estructurales, una secuencia de procesos realmente existentes cuyos efectos intenta abordar, a partir de constructos conceptuales, la ciencia. El objeto de conocimiento, entonces, que no encuentra su réplica en lo real, puesto que no es más que una construcción del pensamiento, nos permite entender (siempre en relación, por ahora, con el formalismo ruso), que la identificación entre

3 En este pequeño párrafo están planteadas, de forma muy general, las tres aristas básicas del problema (el objeto, el método y el problema del conocimiento) y sus implicancias. 
conocimiento y técnica (método) implica siempre en este paradigma formalista, y en términos spinozianos, que el concepto de perro ladra: en otras palabras, que a medida que el saber sobre un objeto (soporte de la verdad) avanza, la distancia entre el conocimiento y el objeto se reduce poco a poco, por lo que el conocimiento exhaustivo de tal o cual concreto de pensamiento no presenta más complicaciones que la de la perfección de la técnica o, dicho de otra forma, que lo que dotaría de legitimidad a la ciencia no sería sino la "evolución” de los procedimientos técnicos de investigación. ¿Qué hay, pues, con esto? Lo veremos a continuación.

\section{La literaturiedad}

\section{La especificidad del saber}

Dijimos que el formalismo tuvo siempre la incapacidad de caracterizar como un proceso dialéctico y multideterminante la relación del par de elementos objeto-método, justamente por la irresponsabilidad de haber reducido su propio objeto - al modelo neopositivista - a un objeto concreto que contenía de por sí su propio conocimiento, y al reducir la misma práctica científica a un conjunto de conductas automáticas limitada a la aplicación, en clave experimental, de instrumentos genéricos de análisis.

La reducción del conocimiento a una técnica termina por menospreciar la especificidad del saber y la especificidad del trabajo de la construcción del objeto de estudio. Creemos que esta desviación idealista merece su corrección.

Esta consideración acerca del objeto de conocimiento y este enseñoramiento de la práctica metodológica suponían que el saber podía ser reducido a una técnica, y que si de hecho la brecha que separaba al objeto de su conocimiento se acortaba cada vez más esto no sucedía sino porque se habían perfeccionado las herramientas de análisis. No es posible considerar al saber únicamente como el producto lógico de la observación de un objeto; tampoco como expresión notoria del conjunto de "respuestas" producidas por el objeto por el estímulo de las herramientas técnicas. El saber no es el índice de comportamiento del objeto, ni la transliteración discursiva de su disposición. El saber no es la recomposición (por extracción, como dijimos) de aquella esencia que le es íntima y que solo se revela al haber desplazado técnicamente todas sus realidades inesenciales. El saber es, justamente, otra cosa. Macherey lo explica:

Conocer no es, pues, volver a encontrar o reconstruir un sentido latente, olvidado o escondido. Es constituir un saber nuevo; es decir, un saber que agrega algo más a la realidad de la cual parte y de la cual habla. Recordemos que la idea de círculo no es ella misma circular; no es porque haya el círculo que existe la idea de círculo. Y retengamos que la aparición del saber establece una distancia, una cierta separación, y que limitando por esta separación el campo inicial, ella lo convierte en un espacio mensurable, el objeto de un saber (9). 
Y más adelante:

Si queremos concederle al saber su verdadero valor, conservarle cierta consistencia, debemos entonces dejar de considerarlo como un artificio provisional, un camino, un intermediario, que nos acercaría a la verdad, o a la realidad, para ponernos efectivamente en contacto con ella. En otras palabras: es necesario devolverle toda su autonomía (lo cual no quiere decir su independencia), su propia dimensión; reconocerle el poder de producir alguno nuevo, por consiguiente de transformar efectivamente la realidad tal como le es dada (10).

Si bien pudimos constatar que los referentes del formalismo (como Shklovski, Tomashevski y el mismo Eichenbaum) habían sido fuertemente influenciados no solo por la tradición epistemológica del neopositivismo lógico, sino también por el atractivo discurso de la recientemente inaugurada disciplina llamada lingüística y que, por tanto, entendían a grandes rasgos qué suponía constituir un saber nuevo acerca de su objeto de estudio, esto no nos prohíbe destacar un conjunto visible de desviaciones que parecieron oscurecer el proyecto científico de la escuela formal. Es esta desviación, por ejemplo, la que permite que críticos (más bien deberíamos decir defensores) de la escuela formal intenten presentarla menos como un discurso específico que gira en torno a la pregunta de la especificidad de la literatura, cuanto un discurso que, en cierto punto, intenta emular el objeto que estudia. Steiner entendía, por caso, que el formalismo era menos un proyecto que pretendía decir algo nuevo acerca de la literatura, de su composición, de los elementos que la constituían, acerca de, en suma, sus rasgos característicos, cuanto una metapoética que, a caballo de diferentes constructos teóricos, a caballo de diferentes metáforas literarias, poetizaba sobre la literatura. Pau Sanmartín Ortí entendía, por su parte, que todo el programa epistemológico del formalismo derivaba a grandes rasgos de la influencia que el futurismo había tenido en los círculos de debates formalistas, sobre todo en Víktor Shklosvki, cuyo concepto de desfamiliarización (extrañamiento) respondía al objetivo político del futurismo ruso - combatir la automatización perceptiva a través del arte- y que, en tanto el fundamento del estudio formalista era derivado de un proyecto artístico, el formalismo tendía espontáneamente a presentarse también como un arte.

Tenemos entonces que el saber que produce la teoría literaria debería ser, según lo dicho hasta ahora, un tipo de discurso otro que difiere punto a punto del discurso al que aborda. Un discurso que establezca de forma clara el objeto de estudio que pretende abordar, como así también el método construido por y para el objeto en cuestión; un discurso que, en última instancia, no produce sino algo nuevo acerca del objeto que aborda. La relación que puede mantener entonces una obra con su crítica no puede ser por menos - en tanto las naturalezas discursivas son diferentes- la de una diferencia irreductible. El discurso crítico de la teoría literaria nada tiene que ver, ni en su forma ni en su contenido, con el discurso literario. 


\section{La lógica de las continuidades}

Es difícil intentar exponer la lógica de las continuidades de los fundamentos teóricos del formalismo. Es difícil definir en rigor si la concepción del objeto de estudio por parte del formalismo se vio determinada en última instancia por el saludo a un constructo metodológico foráneo y que había, en mayor o menor medida, mostrado buenos resultados en otros espacios del pensamiento obrante; o si la concepción misma del objeto de estudio - replicado, en cierto punto, de las ciencias naturales (el objeto ya dado que la práctica científica disecciona para leer su conocimiento contenido) - derivó en una determinación de las herramientas metodológicas de análisis pertinentes; o si la definición misma del conocimiento como un proceso, en clave empirista, que se deduce de las prácticas de la observación y la sistematización, tuvo alguna clase de influencia sobre las posteriores definiciones del objeto y el método de estudio.

Macherey intenta dar cuenta de lo complejo y entreverado que es la caracterización de la empresa crítica:

Para caracterizar la empresa crítica no basta con describirla empíricamente, es necesario justificar de modo racional su actividad y mostrar que sabe adquirir, en el momento oportuno y a su manera, una forma deductiva. Diremos, entonces, que ella inicia un tipo específico de deducción, aplicando al objeto en cuestión un método que le es apropiado. Pero resulta que el método, como tampoco el objeto, no viene dado desde el comienzo: se determinan el uno al otro conjuntamente. El método es necesario para construir el objeto; pero la competencia del método está a su vez subordinada a la existencia del objeto (23).

Dicho esto, tal vez preguntarse por esta lógica de las continuidades sea simplemente en vano: no porque la resolución del conflicto no pueda resultar interesante, sino sobre todo porque es probable que la misma práctica concreta sobre los textos de la literatura, en el caso de la escuela formal, se haya desarrollado a la par del edificio teórico que habría de darle su sustento; porque tal vez no hubo un elemento que terminase por determinar de manera unilateral y directa a los otros elementos comprendidos por la práctica científica en un sentido general, sino más bien porque cada uno de los elementos intervino en la definición y posición que ocuparían los otros en el esquema de esta teoría, y así de forma recíproca. Y no podemos cansarnos de repetirlo: si no intentamos exponer en clave histórica el desarrollo del pensamiento formalista es porque nuestro trabajo no es, justamente, histórico, sino epistemológico. Nos importa más bien la interrelación entre los tres elementos que venimos trabajando: objeto, método y saber, o al decir de Bachelard, la interrelación entre la materia, el medio y el producto. En todo caso, la dificultad real que supone la exposición de esta lógica, e incluso su mismo reconocimiento como un espacio borrascoso de debate, es sintomático de lo complejo que resulta la exposición de las cualidades distintivas de la práctica científica. 


\section{La literaturiedad}

Creemos que el formalismo ruso, a razón de haber enseñoreado el aspecto metodológico de toda práctica investigativa (principio derivado de otros campos del saber que la escuela formal adoptó), terminó por descuidar la definición misma de su objeto de estudio. Es sabido que, en términos muy generales, el objeto de conocimiento del formalismo ruso no mutó, en su formulación, durante largo tiempo. Creemos que, en última instancia, la problemática que intentó establecer el formalismo, la pregunta que el formalismo le hizo a la forma social concreta de la literatura (que no es, claramente, el objeto de estudio, por razones ya evidentes), no varió de forma considerable.

Si bien el círculo ruso pudo mutar tanto programática como epistemológicamente a medida que avanzaban sus estudios, es de destacar que la conceptualización que algunos de sus referentes hicieron del objeto de estudio se mantuvo, durante largo tiempo, inalterado. Mientras Eichenbaum definía al objeto de la ciencia literaria como "el estudio de las particularidades específicas de los objetos literarios que los distinguen de toda otra materia" (37), Jakobson sostuvo que "el objeto de la ciencia literaria no es la literatura, sino la literariedad, es decir, lo que hace de algo una obra literaria" (37). En el primer caso, se nos presenta la posibilidad de estudiar los fenómenos sin la necesidad de establecer una esencia de la literatura a priori; en el segundo caso, por el contrario, la literariedad, es decir, el criterio de selección espontánea, no es defendida sino como un presupuesto atemporal, una especificidad irreductible. Aunque las diferencias entre el fenomenismo del primero y la propuesta fenomenológica del segundo son por el momento irrelevantes, no podemos dejar de afirmar lo siguiente: ambos se vuelcan a una constatación de facto: hay textos literarios.

A pesar de todo, aquí se abre la reflexión acerca del segundo presupuesto que queríamos revisar: el de la existencia de un conjunto de rasgos distintivos que hacen de un texto cualquiera un texto literario, la literaturiedad. Que la afirmación implícita de los dos supuestos - la de la existencia de textos literarios y la de la literaturiedadsea, de forma muy general, la misma (hay un dominio autónomo, por sí y para sí, que contiene a los textos literarios), no impide establecer las diferencias teóricas pertinentes, no solo por lo que implican epistemológicamente, sino también por las posibilidades de análisis que se abrieron a partir de su conceptualización.

Este segundo presupuesto es completamente diferente al primero que analizamos ("hay textos literarios"): no expresa la existencia de un campo, o de un dominio independiente a la práctica científica sino más bien la condición misma de existencia (esta vez sí, en clave teórica) de este campo. En otras palabras: si efectivamente existía un dominio que incluía a todas las obras de la literatura era simplemente porque los elementos que la componían compartían una característica específica como lo es la literaturiedad. El giro es evidente: si en un principio lo que se pretendía hacer era someter a un análisis riguroso a aquellos elementos que espontáneamente se encontraban reunidos en un campo llamado "lo literario", en adelante el formalismo 
intentó definir qué o cuáles eran aquellas reglas que regían la constitución misma de ese dominio; si en un principio el formalismo había tomado por dado el objeto de su teoría, en tanto preexistía - y desde siempre - a la práctica científica, en adelante el formalismo intentó exponer que si había algo así como un dominio preexistente que nucleaba a lo literario era porque ese mismo espacio estaba conformado a partir de reglas particulares que debían ser expuestas en su específica racionalidad. Para reformular lo dicho en una oración un tanto más simple: mientras aquello que le importaba al formalismo temprano era el estudio en clave empírica de una obra literaria, en adelante el interés del formalismo giró hacia el estudio teórico de la condición de emergencia de un discurso como el literario.

\section{El extrañamiento}

Antes de continuar con la caracterización de la idea de literaturiedad, se vuelve necesario un paréntesis, puesto que, de no ser por una breve pausa, siempre dinámica e indagatoria, perderíamos de vista uno de los más famosos textos formalistas. Hablamos de "El arte como artificio" de Víktor Shklovski, publicado en el año 1917. El estudio detenido de este texto fue para nosotros crucial. Intentaremos dar las razones.

En su texto, Shklovski debate con la tradición de pensamiento dominante en relación a la reflexión del arte en los primeros años del siglo xx, encabezada por el filósofo y lingüista Alexander Potebnia. No nos interesa el debate en tanto tal sino las conclusiones a las que arribó Shklovski, tanto teóricas como programático-analíticas. El punto de partida de la crítica shklovskiana se encuentra en la negación del principio fundamental del círculo de Potebnia, que afirmaba que el arte era un pensamiento por imágenes y que, por ende, el estudio acerca de la historia del arte no debería ser sino una historia de la imagen y sus mutaciones a lo largo del tiempo. A propósito de este problema, Shklovski dice:

Pero ocurre que las imágenes son casi inmóviles: de siglo en siglo, de país en país, de poeta en poeta, se transmiten sin cambiarse; las imágenes no provienen de ninguna parte, son de Dios. Cuanto más se conoce una época, más uno se persuade de que las imágenes que consideraba como la creación de tal o cual poeta fueron tomadas por él de otro poeta casi sin modificación. Todo el trabajo de las escuelas poéticas no es otra cosa que la acumulación y revelación de nuevos procedimientos para disponer y elaborar el material verbal, y consiste mucho más en la disposición de las imágenes que en su creación. Las imágenes están dadas: en poesía las imágenes son más recordadas que utilizadas para pensar (79).

He aquí uno de los principios fundamentales del formalismo: el arte es siempre una dación de forma. Esto no implica, como han querido ciertos críticos, que el formalismo despreció el contenido de las obras de la literatura por la exaltación de los procedimientos estéticos de producción; esto implica, más bien, que incluso el contenido (la 
materia, dirían los formalistas), incluso él, está formado. Aquí, y de forma clara, la dación de forma es la condición de existencia de un objeto estético. Shklovski establece al respecto una distinción pertinente:

El objeto puede ser entonces: 1) creado como prosaico y percibido como poético;

2) creado como poético y percibido como prosaico. Esto indica que el carácter estético de un objeto, el derecho de vincularlo a la poesía, es el resultado de nuestra manera de percibir; nosotros llamaremos objetos estéticos, en el sentido estricto de la palabra, a los objetos creados mediante procedimientos particulares, cuya finalidad es la de asegurar para estos objetos una percepción estética (57).

El cambio es interesante: de la reflexión sobre el arte como una perpetua dación de forma, que supone una práctica de producción (esto es, un agente) torcemos hacia la reflexión acerca de la percepción (guiada por la técnica compositiva) de quien recepta aquello que entendemos por arte. En cierto modo, el esquema materialista del primer enunciado (el arte es una dación de forma) no difiere en mucho al de esta segunda etapa del problema. Es decir, si de lo que se trata es de asegurar un reconocimiento de un objeto como estético por parte del receptor es porque este objeto ha sido producido a través de específicos procedimientos que aseguran que sea percibido como tal. De esto se derivan dos problemas: el primero, que ya lo vimos, que refiere a la percepción, esto es, a la abstracción, nunca automática y siempre mediada por, en este caso, procedimientos de dación de forma específicos; el segundo, que no trataremos aquí, pero que se nos presenta como una contradicción: Shklovski mismo afirma que es probable que un objeto concebido como estético no sea percibido como tal, y viceversa, por lo que la construcción de un objeto cuya finalidad es ser caracterizado por el receptor como estético no siempre es infalible.

Volvemos: si el objeto estético es tal no solo por los procedimientos concurrentes a su creación ${ }^{4}$ sino también por el juicio que de él hace quien percibe ese objeto no es sino porque, para Shklovski, todo objeto estético tiende hacia quien lo observa. En otras palabras: el objeto estético tiende siempre a quien lo percibe no de forma espontánea sino más bien porque la percepción es, en última instancia, la finalidad del objeto estético. El problema articulante del texto de Shklovski parece ser entonces el de la percepción:

Si examinamos las leyes generales de la percepción, vemos que una vez que las acciones llegan a ser habituales se transforman en automáticas. De modo que todos nuestros hábitos se refugian en un medio inconsciente y automático. [...] En este método algebraico de pensar, los objetos son pensados en su número y

4 Aquí es necesario realizar una aclaración. Dijimos anteriormente que el formalismo en su teoría literaria había excluido de la reflexión analítica la problemática del sujeto; es decir, la problemática del concepto del sujeto según como había sido planteada por la filosofía moderna. Seguimos defendiendo esto. Ahora bien, esta exclusión no debe confundirse con el hecho insoslayable de que el formalismo nunca dejó de defender la idea según la cual toda forma artística es, casualmente, formada, y que como tal (es decir, como producto de un artificio) precisa de un agente social efectivo que lleve a cabo esa tarea. 
volumen; no son vistos, sino reconocidos a partir de sus primeros rasgos. [...] En el proceso de algebrización, de automatización del objeto, obtenemos la economía máxima de las fuerzas perceptivas: los objetos están dados por uno solo de sus rasgos (82-3).

Y más adelante, estableciendo una relación un tanto más férrea entre el problema de la percepción y del arte:

Así la vida desaparece transformándose en nada. La automatización devora los objetos, los hábitos, los muebles, la mujer y el miedo a la guerra. "Si la vida compleja de tanta gente se desenvuelve inconscientemente, es como si esa vida no hubiese existido". Para dar sensación de vida, para sentir los objetos, para percibir que la piedra es piedra, existe eso que se llama arte. La finalidad del arte es dar una sensación del objeto como visión y no como reconocimiento: los procedimientos del arte son el de la singularización de los objetos, y el que consiste en oscurecer la forma, en aumentar la dificultad y la duración de la percepción. El acto de percepción es en arte un fin en sí y debe ser prolongado. El arte es un medio de experimentar el devenir del objeto: lo que ya está "realizado" no interesa para el arte (84).

Dentro de esta perspectiva, la imagen (o más bien dicho la disposición de las imágenes) no pretende dar a conocer la significación que ellas contienen, esto es, aquello sobre lo que la forma artística se asienta, sino por el contrario lo que pretende la imagen es crear una percepción específica del objeto. La creación, por parte del arte, no del reconocimiento sino de la visión del objeto, nos obliga a pensar que la finalidad del arte se concreta en tanto tal siempre fuera del espacio artístico; que la delicadeza o destreza con la cual un objeto estético fue confeccionado es siempre sometida a juicio no necesariamente por lo que ella es de forma efectiva, sino por sus efectos. El arte se realiza en tanto tal (satisface su función, podríamos decir) si logra resquebrajar en el receptor el esquema algebraico de percepción. Todo parece indicar que en Shklovski el arte sí tiene una función epistemológica, que es el arte una de las formas de pensamiento que permite poner en paréntesis la espontánea relación algebraica y automatizada que mantenemos con las cosas del mundo. Y justamente aquí es donde se abre un problema central: si el proceso de singularización es una forma muy particular de abstracción que recorta parte de lo real para observarlo en su especificidad, y para crear a partir de ello algo nuevo, como lo es su conocimiento (o su visión, al decir shklovskiano); si esta abstracción, decimos, no pretende establecer con el objeto ninguna relación utilitaria, pero si tampoco pretende subsumirlo a una categoría totalizante, entonces, ¿no es en cierto modo similar la operación que realiza tanto la ciencia — como la venimos exponiendo - como el arte — en su comprensión shklovskiana-? Si en efecto las operaciones y el producto de las operaciones son similares, ¿dónde se encuentra la especificidad del arte y dónde la de la ciencia? 


\section{La literaturiedad II (problemáticas)}

La conceptualización acerca de la literaturiedad fue en definitiva eso: el desplazamiento de la pregunta del fin con arreglo al cual se ordenaba la práctica artística (la finalidad de su percepción), por la pregunta acerca del material mismo que ya no la práctica artística, sino más bien la literatura utilizaba para la construcción de sus objetos estéticos. La búsqueda del elemento distintivo que hacía de un discurso uno literario debió realizar obligatoriamente un movimiento reflexivo que se circunscribiera de forma exclusiva a las operaciones discusivas de los textos de la literatura. El movimiento centrífugo que inauguraba la pregunta acerca del objeto estético siempre tendiente hacia quien lo receptaba difiere en mucho del movimiento reflexivo al que invitaba la pregunta por la literaturiedad.

Si en cierto punto ambas búsquedas no pudieron desarrollarse en conjunto no fue sino porque se trataba de dos problemáticas diferentes, al decir althusseriano; de dos diferentes conjuntos de preguntas que el formalismo pretendió hacerle a aquello que creía era su objeto de estudio.

En relación con el problema del objeto estético construido hacia fuera del proceso estético, es evidente que la pregunta que intentó establecer el formalismo terminó por indagar en 1) la caracterización de la finalidad de la obra de arte en tanto tal (como hemos dicho anteriormente, el fin con arreglo al cual la práctica artística tendía espontáneamente), y 2) una antropología de la percepción, y de qué modo esta percepción podía agudizarse a través de la experiencia artística (pero también, como hemos aclarado, a través de la experiencia científica). En este marco colocamos debidamente al trabajo de Shklovski, motivado por las preguntas de la primera etapa formalista, es decir, aquellas que se veían encabezadas por el presupuesto de la existencia de los textos literarios. Entendemos que la razón sería simple: si en efecto los textos literarios existían independientemente de cualquier otra práctica, y si en definitiva los textos literarios hacían explícita su especificidad en tanto textos literarios en su misma materialidad, el estudio de la literatura debía limitarse, en principio, al estudio de su función. Una afirmación de este tipo es sin dudas polémica. No intentamos decir aquí que Shklovski no se preguntó en absoluto por los mecanismos discursivos a través de los cuales los textos literarios se constituían como tales, sino que el foco de sus análisis abordaba de forma más estricta otros órdenes que, hasta ahora, creemos que no han sido destacados con la seriedad que ameritan. En todo caso, sí creemos que es sintomático que en el texto que nombramos de Shklovski la distinción entre una función poética o prosaica de la lengua no aparezca sino como una idea, una noción vaga, una expresión de tintes metafóricos. Esta distinción nace como concepto, como idea articulante tiempo después, cuando la problemática que estableció el formalismo refirió casi de forma exclusiva a los procedimientos discursivos, formantes del fenómeno de la literatura.

En relación con el segundo problema, es decir, el de la literaturiedad, el formalismo intentó volver sobre sus pasos. Si bien no dejaba nunca de considerar que en efecto 
existía aquello que habíamos dado en llamar “textos literarios”, el formalismo intentó despejar los elementos que hacían de esta afirmación una afirmación válida. Aquí, el problema para el formalismo ya no era la función estética de la obra de arte (lo que volvía inoperante la aparente contradicción entre dos especificidades irreductibles como las del arte y la ciencia), sino los regímenes compositivos mismos de la obra. El estudio de la materialidad de los textos llevó a la escuela formal a preguntarse de forma directa por el material con el que trabajaban las obras de la literatura: este material no eran las imágenes (que no le pertenecían al arte, sino a Dios — como decía Shklovski-) sino la lengua misma.

Solo a partir del supuesto de la literaturiedad —cuyo núcleo es el problema de la lengua - es que se hizo posible el estudio inmanente de los textos de la literatura. Es decir: fue la pregunta por el material de la literatura la que permitió indagar en la literatura como una expresión radical de una victoria de la lengua, en la literatura como una celebración de la lengua (por trágico que sea aquello que la lengua narra), en la literatura como una forma expresiva que nada tiene que ver el color de la bandera nacional (al decir de Shklovski).

\section{Hacia el posformalismo}

Existían detractores, sin embargo, a esta propuesta. Incluso dentro de las filas formalistas. Si en efecto los textos literarios existían así sin más, si en efecto la pregunta por el origen - o el comienzo- de la literatura es inconducente, es porque el concepto (la literaturiedad) que funciona como su condición (como condición de la existencia de los textos), además de implicar la existencia previa de un sujeto y de un objeto (y de un objeto que ya contiene en sí su propio conocimiento), es un concepto obligatoriamente sustraído al tiempo. En esta sustracción al tiempo, este supuesto tiende a eliminar, en el afán de establecer una ciencia de nada más que de la literatura, toda posibilidad de estudio de elementos extrínsecos al proceso artístico que participan en la constitución de la literatura en tanto tal, y con ello, la limitación del estudio a las materialidades textuales. A su vez, este supuesto parece indicar que el campo de la literatura existe por sí y para sí (lo que no constituye una proposición analítica, sino ontológico-efectiva), ajeno a toda determinación extrínseca. Este principio operativo pudo redirigir la práctica analítica en dos direcciones: en primera instancia, como ya hemos visto, la prefiguración incipiente de una apuesta fuerte por un estudio inmanente de la literatura; ${ }^{5}$ en segunda instancia, el formalismo temprano vio clausurada

5 La posibilidad de un estudio inmanente es, a nuestro entender, una invectiva de los estudios de la literatura que debería ser aún profundizada. De a momentos, críticos literarios (y sobre todo aquellos de filiación marxista, como Eagleton, que escribe un texto fundamental, "Introducción: ¿qué es literatura?", en Una introducción a la teoría literaria, en oposición al formalismo), intentaron representar a la escuela formal como un proyecto pequeño burgués que, alejado de toda problemática social efectiva, negó la relación entre la vida (byt, en ruso) y el arte. Hay en esta crítica un acierto y un desacierto. Un acierto: es evidente que de a momentos ciertos formalistas, tal vez los más polémicos (como Shklovski), intentaron defender la idea según la cual no existían puntos concretos de contacto entre 
la posibilidad de un estudio que comprendiese en clave extensiva el problema de la historia en la conformación misma del dominio que se pretendía abordar, este es, el de la literatura.

Son problemáticas que deberán ser estudiadas con la seriedad que ameritan. Será momento entonces de emprender un camino de largo aliento.

\section{Referencias}

Althusser, Louis. Iniciación a la filosofía para los no filósofos. Buenos Aires, Paidós, 2015. Althusser, Louis y Étienne Balibar. Para leer El Capital. Madrid, Siglo xxi, 2010.

Bachelard, Gaston. La formación del espíritu científico: contribución a un psicoanálisis del conocimiento objetivo. Buenos Aires, Siglo xxI, 1991.

De Saussure, Ferdinand. Curso de lingüística general. Buenos Aires, Losada, 2015.

Eichenbaum, Boris. "La teoría del 'método formal". Teoría de la literatura de los formalistas rusos. $3^{a}$ edición, México, Siglo xxi, 1978.

Erlich, Victor. El formalismo ruso. Barcelona, Seix Barral, 1974.

Jakobson, Roman. "Sobre el realismo artístico". Teoría de la literatura de los formalistas rusos. $3^{\text {a }}$ edición, México, Siglo xxi, 1978.

Macherey, Pierre. Para una teoría de la producción literaria. Caracas, Universidad Central de Venezuela, 1974.

Propp, Vladimir. "Las transformaciones de los cuentos fantásticos". Teoría de la literatura de los formalistas rusos. $3^{\mathrm{a}}$ edición, México, Siglo XxI, 1978.

Sanmartín Ortí, Pau. La finalidad poética en el formalismo ruso: el concepto de desautomatización. Madrid, Universidad Complutense de Madrid, 2006.

Shklovski, Víktor. "El arte como artificio". Teoría de la literatura de los formalistas rusos. $3^{\text {a }}$ edición, México, Siglo xxi, 1978.

Steiner, Peter. El formalismo ruso, una metapoética. Madrid, Akal, 2001.

\footnotetext{
las producciones literarias y lo social en términos generales. Esto le permitió al primer formalismo llevar a cabo un estudio que olvidase el complejo juego de interrelaciones que suponen las prácticas de lo social en beneficio de un estudio que no versase sobre otra cosa más que los mecanismos productivos de las obras literarias. (Si esta apuesta fue defendida por razones estratégico-políticas o por razones teóricas duras nos importó menos, como ya hemos destacado, que los fundamentos epistemológicos que terminaban por darle sustento a un estudio en esta clave, y sus implicancias epistemológicas). Un desacierto: una afirmación de este calibre habla de una lectura irresponsable del pensamiento formalista. El formalismo no dejó nunca de destacar - aunque en sus inicios era un señalamiento siempre testimonial - que la serie literaria establecía sin lugar a dudas relaciones con otras series de las prácticas de lo social, y que el estudio de sus interrelaciones debería ser profundizado. El estudio de estas relaciones se hizo demorar: fueron Jakobson y Tinianov que intentaron sentar las bases teóricas de su estudio a finales de los veinte y que marcarían, a nuestro entender, una nueva etapa de los estudios de la literatura que difícilmente puedan llegar a ser considerados como exclusivamente formalistas. Tinianov diría, en un texto publicado en el 1928 llamado "Sobre la evolución literaria": "La existencia de un hecho como hecho literario depende de su cualidad diferencial (es decir de su correlación, sea con la serie literaria, sea con una serie extraliteraria); en otros términos, depende de su función. Lo que es 'hecho literario' para una época será un fenómeno lingüístico dependiente de la vida social para otra y viceversa, según el sistema literario con referencia al cual se sitúa ese hecho" (Tinianov, 124).
} 
Tinianov, Yuri. “Sobre la evolución literaria”. Teoría de la literatura de los formalistas rusos. $3^{\text {a }}$ edición, México, Siglo Xxi, 1978.

Todorov, Tzvetan, editor. Teoría de la literatura de los formalistas rusos. $3^{\text {a }}$ edición, México, Siglo Xxi, 1978.

Tomashevski, Boris. "Sobre el verso". Teoría de la literatura de los formalistas rusos. $3^{\text {a }}$ edición, México, Siglo xxi, 1978.

Enviado: 22 de enero de 2018

Aceptado: 10 de octubre 2018 